\title{
A Inclusão do Surdo e seus Desafios na Educação Infantil
}

\author{
Evilázia Matias de Sousa Silva ${ }^{1}$; Aurelania Maria de Carvalho Menezes ${ }^{2}$
}

\begin{abstract}
Resumo: Tendo em vista que o tema inclusão cada vez mais é discutido em muitos aspectos, esta pesquisa acadêmica, procurou focar o referido tema voltando ao universo do estudante surdo desde sua inserção na Educação Infantil. Este estudo teve como metodologia, uma revisão bibliográfica, de natureza qualitativa e descritiva, considerando as contribuições de autores comprometidos com a causa, como Moura (2000), Fernandes (2003), entre outros que enfatizam a educação inclusiva e seus sujeitos, o aluno surdo e o professor. Inicialmente fez-se uma abordagem sobre a inclusão do aluno surdo e em seguida uma reflexão sobre a formação do educador da sala comum na perspectiva inclusiva, a grande importância do Atendimento Educacional Especializado-AEE no processo de ensino e aprendizagem destes alunos e a função do interprete de Libras. Aborda a inclusão escolar como uma política que consiste no acesso e na permanência de todos os alunos com deficiência nas redes de ensino. A pessoa com surdez apresenta uma limitação sensorial que requer adequações e materiais pedagógicos específicos que facilitem seu processo de aprendizagem. Pretendem-se com este estudo proporcionar subsídios para os professores e estudantes nesta etapa de ensino inicial, como também professores da sala de AEE, referenciais e pistas que possam apoiá-los na inclusão educacional desses alunos. Dessa forma para que haja a inclusão escolar do aluno surdo, as instituições de ensino devem rever sua prática pedagógica, desenvolvendo mecanismos e práticas, considerando a diferença desse alunado, promovendo o pleno desenvolvimento das suas potencialidades no contexto educacional e para o favorecimento do processo ensino aprendizagem de seus educando.
\end{abstract}

Palavras - chave: Aluno surdo. Educação inclusiva. Educação infantil. Intérprete. Professor.

\section{Inclusion of the Deaf and its Challenges in Early Childhood Education}

Abstract: Bearing in mind that the inclusion theme is increasingly discussed in many aspects, this academic research focuses on that theme, returning to the universe of the deaf student since its insertion in Early Childhood Education. This study had as methodology, a bibliographic review, of qualitative and descriptive nature, considering the contributions of authors committed to the cause, such as Moura (2000), Fernandes (2003), among others that emphasize inclusive education and its candidates, the student deaf and the teacher. Initially, an approach was made on the inclusion of the deaf student and then a reflection on the education of the common room educator in an inclusive perspective, a great importance of Specialized Educational Service-AEE in the teaching and learning process of these students and the role of the Libras interpreter. It addresses school inclusion as a policy that consists of the access and permanence of all students with disabilities in education networks. The person with deafness has a sensory limitation that requires specific adaptations and pedagogical materials that facilitate their learning process. The aim of this study is to provide subsidies for teachers and students at this stage of initial education, as well as teachers in the ESA room, references and clues that can support the inclusion of education in these students. Thus, in order for school inclusion of the deaf student, as educational institutions they must review their pedagogical practice, developing mechanisms and practices, considering the difference of this student, promoting the full development of their potentialities in the educational context and for the favoring of the process of education. teaching learning to your learner.

Keywords: Deaf student. Inclusive education. Child education. Interpreter. Teacher.

${ }^{1}$ Faculdade de Ciências Humanas do Sertão Central (FACHUSC). evilazia.silva@ fachusc.com;

${ }^{2}$ Faculdade de Ciências Humanas do Sertão Central (FACHUSC). lelamenezesluiza@yahoo.com.br. 


\section{Introdução}

Para a criança surda está inserida na primeira etapa da Educação Básica é um desafio, são tantos os obstáculos que muitos se limitam ao seu processo de aquisição da leitura e escrita quando se trata da questão da alfabetização, encontra-se uma defasagem nesse processo onde se restrita na falta de infraestrutura e qualificação profissional na área, é importante destacar que a educação inclusiva é essencial para que ocorra o desenvolvimento das habilidades fundamentais da criança surda, propondo-se assim uma aprendizagem relevante e eficaz para esse aluno.

Na organização pedagógica das instituições, é necessário considerar a dimensão pessoal do profissional docente frente à realidade da inclusão. Há uma necessidade de propor formas adequadas de ensino, avaliação adaptada respeitando as peculiaridades dos estudantes com deficiência auditiva, tomada de decisões coerentes com a proposta curricular e garantir formação continuada aos docentes para atuar com estudantes com surdez.

Aceitação e a disponibilidade do professor para lidar com essa criança constituem requisitos necessários, mas não suficientes. O importante é o professor conhecer suas possibilidades em seu ato de aprender e as condições necessárias para que ocorra seu desempenho. Desta forma, acreditando na inclusão como um instrumento de mobilização para a reflexão das práticas de ensino que se devem considerar a necessidade de iniciar o processo de mudança, a começar pela formação do professor, como condição fundamental para a educação inclusiva.

Nesse contexto torna-se urgente um redirecionamento na postura e no papel do professor, para que este planeje seu trabalho em uma perspectiva inclusiva, fazendo uso da pedagogia da diversidade, com aulas que não visem apenas a permanência destes alunos na sala, mas que obtenham resultados acadêmicos e sociais satisfatórios.

Sabe-se que muitas crianças surdas estão frequentando as escolas em classes organizadas e pensadas para alunos ouvintes, fazendo com que a mesma seja obrigada a acompanhar aulas planejadas para alunos ouvintes. Normalmente estas crianças futuramente se tornam excelentes copistas, mas com grande deficiência na aquisição de conhecimentos no geral e principalmente na linguagem escrita. Nesse contexto surgiu a seguinte questão o professor da educação infantil está realmente preparado para atender as necessidades do aluno surdo no contexto da diversidade para que de fato atenda o que diz a lei que a educação é direito 
de todos?

Com isso, este artigo científico de abordagem qualitativa e bibliográfica tem como objetivo discutir os desafios encontrados no processo de ensino aprendizagem da criança surda no ensino infantil e o trabalho do professor nas salas de alunos surdos inclusos, suas estratégias e metodologias, bem como sua visão de ensino inclusivo. Pois, a Educação inclusiva é uma prática pedagógica que é capaz de educar com sucesso todos os alunos, mesmo aqueles comprometidos. Está fundamentada pela LDB n. 9.394/96 e pela Constituição Federal que garante a todos o direito à educação.

Entende-se que, estar a criança surda dentro da educação infantil só alcançará resultados satisfatórios se no espaço escolar for contemplada sua condição linguística, cultural e curricular especiais, onde haja educadores sensibilizados, que tenham uma visão de como deve ser o trabalho em classes onde exista aluno surdo incluso, para que estes possam adquirir incentivo, autonomia, espírito crítico, criatividade, passando a exercer a sua cidadania de forma eficaz.

\section{A Inclusão do Estudante Surdo na Educação infantil}

A Educação Inclusiva acontece de forma dinâmica e objetiva onde atenderá a diversidade, pois os educadores que trabalham com a inclusão na educação infantil devem reconhecer e atender as diversas necessidades de seus discentes, acomodando-se aos ritmos e estilos de aprendizagem e assegurando assim uma educação de qualidade a todos através de uma base curricular apropriada, através de estratégias de ensino, usos de recursos, arranjos organizacionais e parceria com as comunidades.

No ano de 1994 durante a Conferência Mundial de Educação Especial houve a aprovação da Declaração de Salamanca, essa lei passou a acatar a inclusão dos alunos com necessidades especiais em classes na primeira etapa de ensino e os demais níveis, como a forma mais avançada de democratização das oportunidades educacionais.

A Declaração de Salamanca (1994), aborda que:

Cada criança tem o direito fundamental à educação e deve ter a oportunidade de conseguir e manter um nível aceitável de aprendizagem. Cada criança tem características, interesses, capacidades e necessidades de aprendizagem que lhe são próprias. Os sistemas de educação devem ser planeados e os programas educativos implementados tendo em vista a vasta diversidade destas características e necessidades. (DECLARAÇÃO DE SALAMANCA, 1994). 
Este documento é considerado um dos principais em relação a base mundial, propondo assim uma visão à inclusão social. Com isso, defende-se a "educação de qualidade para Todos" tem a ver com a inclusão de todos os alunos nas instituições escolares sem restrição social.

Essa declaração defende, com relação ao ensino-aprendizagem, a ideia que o conteúdo curricular deve atender às necessidades educacionais da criança surda, com o propósito de participarem de forma efetiva e plena, através do seu desenvolvimento, cognitivo e motor.

Para Moura (2000), a trajetória educacional das pessoas surdas foi marcada por muita luta no que diz respeito a oficialização da Língua de Sinais, tanto no âmbito internacional quanto no nacional. No caso do Brasil, a Língua de Sinais sofreu algumas mudanças quanto à sua nomenclatura e é atualmente denominada por Língua Brasileira de Sinais. Ela foi reconhecida como língua, por meio da Lei Federal n 10.436, de 24 de abril de 2002 que a oficializou com esse status.

É nesta lei que reconhecemos a LIBRAS como a principal língua materna dos surdos, sendo de grande relevância na conquista dos seus direitos dentro do contexto social, educacional e profissional. Havendo uma mudança de sua realidade, garantindo assim por lei que o aluno surdo precisa ser ensinado em sua própria língua. Há também o Decreto de Lei no ${ }^{\circ} 5.626$ de 22 de dezembro de 2005 que assegura o uso obrigatório da LIBRAS, em todas as instituições educacionais, onde o discente tem acesso independente de sua deficiência para acontecer de fato a sua inserção, tanto em sala de aula quanto fora desta e, especificamente, nas escolas especiais, onde encontram suporte necessário às suas necessidades educacionais especiais e menos apoio nas escolas comum, porque tal paradigma ainda não foi implementado com eficiência.

Diante disso, as escolas principalmente da educação infantil não estão totalmente preparadas para lidar com o aluno surdo, provocando insegurança em recebê-lo, pois a equipe escolar como um todo, não sabe como atender às suas necessidades especiais para propor a esse aluno uma educação de qualidade. Porém, a inclusão oferece de forma radical subsidios para incluir essa criança, sem excluir ou discriminar as suas diferenças. Enfim, para que a inclusão do surdo aconteça de fato é necessário muitos alinhamentos nas políticas públicas.

\section{AEE: Importância no processo ensino e aprendizagem}

Oficializado em setembro de 2008, pelo Decreto Presidencial n ${ }^{\circ} 6.571$, o Atendimento 
Educacional Especializado-AEE, é uma Política Pública e foi criada para favorecer a Educação Inclusiva, e seu objetivo é complementar e suplementar as condições de formação integral do educando, garantindo serviços, recursos de acessibilidade e várias estratégias que eliminem as barreiras encontradas que dificultem a plena interação social. Assim, o professor precisa apoiarse nestes profissionais, construindo um trabalho de parceria em favor do educando surdo.

O AEE acontecerá em salas de recursos dotadas de equipamentos, materiais pedagógicos, ministrada por profissionais especializados que atendem estes alunos em horário contrário ao de sua turma no Ensino infantil. Vale salientar que estes profissionais não darão aulas de reforço, mas sim, usarão vários recursos didáticos e pedagógicos objetivando a eliminação de barreiras existentes ou que surgem no processo de ensino e aprendizagem. Sendo assim, o educador do Atendimento Educacional Especializado precisa elaborar um plano individualizado que contemple o desenvolvimento cognitivo, social, afetivo e linguístico. Essa modalidade de ensino percorre todos as etapas e graus na trajetória escolar do sujeito e visa identificar as necessidades e possibilidades do educando com deficiência, desenvolvendo planos de atendimento onde vise o acesso e à participação no processo de escolarização em escolas regular.

A maioria das crianças surdas chegam à escola sem domínio de uma língua, ou seja, conhecem de forma precária a Língua Portuguesa e têm, geralmente, quase nenhum contato com a LIBRAS, a tarefa mais importante do AEE é a criação de espaços que propiciem a aprendizagem da Língua Brasileira de Sinais, pois ela é uma língua espacial-visual e certamente, existem inúmeras formas criativas de explorá-la. Para tanto, os professores precisam contemplar aulas que se utilize o concreto, imagens, jogos, associações de ideias, discriminação visual, comunicação espontânea, práticas de leitura diversas, produções escritas entre outras.

Mesmo diante de tantas propostas de atividades para explorar o desenvolvimento do estudante surdo, incluí-lo em salas da educação infantil é um desafio difícil, pois os professores não entendem que há uma diferença linguística irrecuperável, em relação aos ouvintes. A realidade é que a maioria dos professores não dominam os aspectos fundamentais para compreender como acontece o aprendizado de um aluno surdo. Além disso, veem na surdez, um elemento limitador entre as necessidades de aprendizagem e desenvolvimento dos discentes surdos e nesse sentido, não compreendem a surdez enquanto característica peculiar de um 
sujeito que não a impede ou incapacita de ser, de viver em sociedade, de envolver-se com a comunidade em todas as suas atividades.

Na Educação Infantil, o trabalho pedagógico deve ser construído e desenvolvido em um ambiente bilíngue. Com isso, destacam-se três momentos didático-pedagógicos, conforme Godói (2012):

- No primeiro Momento todos os conhecimentos dos diferentes conteúdos curriculares deverão ser explicados em Libras por um instrutor, esse trabalho deve ser continuo para que de fato aconteça a interação na aprendizagem. Para que isso aconteça, é necessário aplicar uma didática dinâmica onde se trabalhe com muitas imagens visuais e de todo tipo de referências que possam colaborar para o aprendizado dos conteúdos curriculares em estudo, na modalidade infantil.

- O Segundo Momento os alunos precisam obter aulas de Libras, favorecendo a aprendizagem significativa e a aquisição da leitura e escrita. Este trabalho deve ser realizado pelo instrutor, de acordo com o estágio de desenvolvimento em que o aluno se encontra dentro da linguagem de sinais. Além disso, o atendimento deverá ser planejado a partir do diagnóstico do conhecimento que o aluno tem a respeito da Língua de Sinais.

- Já no terceiro Momento em relação ao ensino da Língua Portuguesa no atendimento especializado para o aluno surdo deverá ser trabalhada as características dessa língua. Este trabalho deve ser realizado todos os dias à parte das aulas da turma comum. Sendo de forma planejada e organizada a partir do diagnóstico do conhecimento que o aluno tem a respeito da Língua Portuguesa.

É necessário buscar meios para a inclusão de crianças com surdez na educação infantil e nas demais etapas de ensino, visando sua participação e aprendizagem nas salas de aula regular e também no Atendimento Educacional Especializado. Para tanto, é necessário que toda a comunidade escolar esteja envolvida no processo, conhecendo este espaço, e trabalhando em parceria com o mesmo.

Com isso, se torna indispensável a interação do instrutor do AEE com o educador da sala comum, pois é este especialista que apontará se há ou não a necessidade do AEE para produzir recursos pedagógicos e de acessibilidade para o desenvolvimento de algumas atividade ou conteúdo específico. Por sua vez é importante que o professor do AEE, mantenha um diálogo aberto com professor regular fazendo com que estes compreendam que existem muitas formas 
e caminhos para ensinar o educando. Para tanto é necessário ampliar as estratégias e recursos, explorando as bases sensoriais principalmente com recursos visuais.

Nesses encontros é preciso ver a possibilidade de flexibilidade de conteúdos ou mesmo a interdisciplinaridade, pois a práxis pedagógica do professor no âmbito inclusivo e interdisciplinar é uma ação conjunta de uma verdadeira troca de saber sendo imprescindível para o desenvolvimento das potencialidades desses educandos. Nesse sentido é importante que o professor entenda que desenvolver um trabalho interdisciplinar é abandonar o currículo fragmentado, o que não implica no abandono das disciplinas, mas sim, em um trabalho em equipe com muitas discussões e reflexões, diversas articulações e ações colaborativas dos profissionais daquela comunidade escolar, compreendendo que todos têm o direito a aprender e a desenvolver em uma escola aberta e flexível.

O ensino da língua Portuguesa escrito não se limita apenas na alfabetização dos alunos com surdez, mas em todas as etapas de letramento. Sendo assim, desde o início do processo de aprendizagem até o ensino acadêmico precisam ser desenvolvidos, tornando indispensável o Atendimento Educacional Especializado para o ensino da língua portuguesa escrita.

No decreto $n^{\circ} 5.626 / 2005$ é citada a figura do instrutor de Libras, que atuará na AEE, desenvolvendo um trabalho de mediador da linguagem e conhecedor da Língua de Sinais e que vai partilhar seu saber de forma lúdica utilizando jogos, brincadeiras, histórias e atividades diversas que atraiam a atenção dos mesmos, buscando a imersão das crianças no universo da Libras. Nesse sentido o objetivo primordial do instrutor de Libras é promover a fluência em Libras de forma prazerosa, para que o aprendizado de outros conhecimentos que circulam no espaço escolar seja apreendido por estes estudantes sem obstáculos linguísticos.

Quando as famílias dos surdos se interessam em aprender a Língua de Sinais facilita muito seu desenvolvimento e aprendizagem. Evitar os gestos e entender que existe uma Língua formal, com estrutura própria, auxilia positivamente inclusive no sucesso cognitivo da criança. Os pais conseguem ajudar nas atividades escolares dos filhos surdos e estar em constante comunicação com a língua materna deles. Então, a Libras não fica relegada apenas ao uso escolar perdendo espaço no cotidiano da pessoa surda, ela integra toda sua vida, do ambiente doméstico ao escolar. 


\section{A formação do professor da sala comum na perspectiva inclusiva}

Sabe-se que para incluir alunos com surdez exige uma preparação do professor que está envolvido diretamente no processo de desenvolvimento da aprendizagem desses discentes. É preciso que os professores envolvidos nesse processo recebam um suporte técnico e uma formação continuada mais voltada a prática pedagógica especifica, para que seja diminuído em parte os desafios encontrados nesse processo de inclusão, já que esses profissionais terão como base a nova filosofia proposta pela "educação para todos", incluindo sujeitos deficientes auditivos ao processo de inclusão, pois, no processo de ensino e aprendizagem, deve-se enfatizar os procedimentos de aprendizagem, e não muito ao acúmulo de informação.

Para os educandos com surdez, assim como para os ouvintes, é muito relevante desenvolver o desejo de saber, de aprender, buscar informações, gostar de ler e a satisfação quando se resolve um determinado problema. Portanto, é importante que o professor na prática pedagógica onde estejam inclusos alunos surdos, ofereça atividades individuais, e e atividades em equipe para que haja a integração com colegas ouvintes. É importante também possibilitar que os alunos surdos realizem tarefas diversas utilizando métodos visuais de comunicação.

Sobre a surdez profunda, Coll; Marchesi; Palacios (2004), explanam que:

(...) O problema mais sério refere-se à educação das crianças surdas profundas. Nesse caso, é preciso ter um objetivo básico: favorecer a comunicação e educar para integração, tanto no mundo dos ouvintes como no mundo dos surdos. Para isso, devese incorporar um duplo sistema de comunicação, oral e visual, e facilitar a integração social e a aprendizagem das crianças com seus colegas surdos e ouvintes. (COLL; MARCHESI; PALACIOS, 2004, p.191).

É necessário entender que no espaço escolar os alunos surdos devem ser vistos por seus educadores como seres únicos, dotados de várias capacidades e potencialidades a serem desenvolvidas e ampliadas, visando a superação de todas as dificuldades inerentes à condição de pessoa surda.

O ideal, no entanto, é que os professores planejem suas aulas junto com o Intérprete de Libras para que haja harmonia nas estratégias a serem utilizadas para explicar os conteúdos, o intérprete pode nortear o professor acerca de que tal recurso vai ajudar o aluno surdo a compreender melhor ou que tal método vai deixar aquele aluno excluso do entendimento. 


\section{O papel do intérprete de libras na inclusão escolar}

O intérprete de Língua de Sinais é o profissional responsável por mediar a comunicação através da interpretação de uma língua oral para uma sinalizada, também realizando o mesmo papel, da língua de sinais para a oralizada. Os alunos surdos precisam ser acompanhados com o auxílio do intérprete da Língua de Sinais, profissional fluente na língua falada/sinalizada do seu país, qualificado para desenvolver essa função (BARBOSA-JUNIOR, 2011).

Para Quadros(2004), o intérprete de LIBRAS:

É o profissional que domina a Língua de Sinais e a língua falada do país e que é qualificado para desempenhar a função de intérprete da Libras. No Brasil, o intérprete da Língua de Sinais deve dominar a Língua Brasileira de Sinais e a língua portuguesa (QUADROS, 2004, p.27).

Este profissional é imprescindível para a eficácia da inclusão do educando surdo na Educação Infantil ou em qualquer etapa de ensino, pois é através dele que será mediada a comunicação dos docentes com o educando surdo e do idioma português para Língua de Sinais. Sua atuação não se limita a essas questões: é necessário adaptar o conteúdo planejado pelo professor, buscando estratégias de ensino que facilitem a aprendizagem do aluno surdo, quando não tiverem condições de realizar os planejamentos no coletivo, professores e intérpretes.

Segundo Fernandes (2003):

(...)planejamento supõe definição de recursos e estratégias de ensino e avaliação sobre aprendizagem. A atuação do intérprete junto ao professor exige um conhecimento a priori do que vai ser ensinado, como vai ser ensinado e como se fará a avaliação da aprendizagem. O roteiro e os caminhos de atuação em sala de aula devem ser interativos não apenas no que se refere ao aluno e ao professor, mas inclui o intérprete, visto que ele não é apenas um elemento facilitador de comunicação, mas a chave para que a comunicação se estabeleça. Assim, é necessário que sua parceria com o professor seja consistente o suficiente para que os objetivos sejam alcançados (FERNANDES, 2003, p. 85).

É tarefa árdua conseguir esse planejamento junto ao professor. No Ensino Infantil é mais fácil porque geralmente a turma tem apenas um professor. Mas a partir do Fundamental I quando as disciplinas são divididas com professores diversos, conseguir um tempo para planejamento com todos é bastante complicado. A maioria dos educadores trabalham em mais de uma escola, têm uma carga horária estafante, muitos fazem seu planejamento na escola entre uma aula e outra, enfim, há várias dificuldades para conseguir um momento com todos. Quando isso acontece resta pedir com antecedência seu planejamento para adaptar, buscar sinais 
específicos, estudar a melhor forma de fazer com que o estudante surdo compreenda um e outro conceito a ser estudado.

Um outro problema está no fato de que boa parte dos professores não se sente à vontade com um intérprete na sala de aula, pois é alguém que está ali observando sua metodologia, suas estratégias, seu domínio de conteúdo, domínio com a turma, alguns professores se sentem intimidados ou desconfortáveis com essa presença.

Os desafios para os tradutores e intérpretes de libras são infindáveis. Muitos estudantes surdos começam a frequentar a escola fora da faixa etária, alguns nunca foram alfabetizados em Libras e nesses casos, não adianta a interpretação simultânea enquanto o professor explica os conteúdos porque o estudante surdo não irá compreender aqueles sinais. Mesmo ele frequentando a Sala de Atendimento Especializado, é insuficiente para aprender a língua e acompanhar todos os conteúdos e as atividades transmitidas em sala de aula.

O intérprete de língua de sinais então, terá que fazer o trabalho de alfabetizador, assim como, ensinar os conceitos, e procurar sempre ensinar novos sinais, fazer o seu trabalho de acordo com a necessidade do aluno, no nível de aprendizagem que ele se encontra. A sala de AEE será também essencial para o desenvolvimento do aluno, mas provavelmente ele será retido. No entanto, conhecimento é cumulativo e dependendo das estratégias, do interesse desse aluno em aprender, logo essas lacunas serão eliminadas.

\section{Metodologia}

Este trabalho de pesquisa possui natureza qualitativa, descritiva e dissertativa, e foi desenvolvido através de estudos bibliográficos de autores como: Moura (2000), Fernandes (2003), Coll; Marchesi; Palacios (2004), que expuseram seus trabalhos expressivos para contribuírem com outros estudos acerca do tema, assim como leis e decretos brasileiros e a tão importante Declaração de Salamanca (1994).

\section{Considerações finais}

O professor sempre foi uma figura de grande relevância para o desenvolvimento da aprendizagem e a formação integral dos educandos, não sendo diferente, para o aluno surdo e seu processo de escolarização. A atuação do educador é marcada por suas experiências e 
habilidades, assim como, por desafios que a prática pedagógica sempre exigiu no cotidiano escolar, pois envolve vários aspectos, como: ensinar, avaliar e planejar. Além disso e de muitos outros trabalhos, o educador é responsável por descobrir e apontar caminhos que contribuam para o desenvolvimento do processo de aprendizagem do educando surdo, de acordo com suas necessidades e possibilidades.

Nesse sentido o presente artigo, de base cientifica, visa contribuir com a aprendizagem do aluno surdo, para que este se desenvolva integralmente, assumindo seu papel importante na sociedade como um cidadão participativo e ativo, cumpridor de seus direitos e deveres, que cabe a todo cidadão.

Além disso, o trabalho em questão, busca fazer uma análise sobre a prática pedagógica do professor no decorrer do processo ensino aprendizagem do aluno surdo na Educação infantil, buscando encaminhar novas estratégias de trabalho que norteie o professor no desenvolvimento de suas aulas, ampliando o conhecimento do mesmo a cerca de um trabalho inclusivo, dinâmico e que respeite a diversidade.

Pois, entende-se que o professor seja ele da Educação Infantil ou não que se dispõe a ensinar alunos surdos, precisará está atento à necessidade urgente de contemplar a singularidade linguística do grupo e buscar meios para que a diferença seja atendida e a inclusão verdadeiramente aconteça.

\section{Referências}

BARBOSA-JÚNIOR, J. A função do tradutor e intérprete de Língua Brasileira de SinaisLIBRAS: âmbitos de atuação e o intérprete educacional. PROFT em Revista, São Paulo, v. $1 \mathrm{n}^{\mathrm{o}} 1$, out. 2011 .

BRASIL. Constituição (1988). Constituição da República Federativa do Brasil. Brasília, DF, Senado, 1998.

BRASIL. Decreto $\mathbf{n}^{0}$ 5.626. Regulamenta a lei 10.436, de 24 de abril de 2002, que dispõe sobre a Língua Brasileira de Sinais - Libras, e o art. 18 da Lei n ${ }^{\circ} 10.098$, de 19 de dezembro de 2000. Publicada no Diário Oficial da União em 22/12/2005.

BRASIL. Decreto $\mathbf{N}^{\circ} \mathbf{6 . 5 7 1}$, de 17 de setembro de 2008. Dispõe sobre o atendimento educacional especializado, regulamenta o parágrafo único do art. 60 da Lei no 9.394, de 20 de dezembro de 1996, e acrescenta dispositivo ao Decreto $\mathrm{n}^{\circ} 6.253$, de 13 de novembro de 2007.

BRASIL. Lei no. 9394/96, 23 de dezembro de 1.996. Lei de Diretrizes e Bases da Educação 
Nacional. Brasília: Ministério da Educação e do Desporto, 1.996.

BRASIL. LEI No 10.436. Dispõe sobre a Língua Brasileira de Sinais - Libras e dá outras providências. Publicada no Diário Oficial da União em 24/04/2003.

COLL, César; MARCHESI, Álvaro; PALACIOS, Jesus. Desenvolvimento Psicológico e Educação. Porto Alegre: Artmed, 2004.

DECLARAÇÃO DE SALAMANCA E LINHAS DE AÇÃO: sobre necessidades educacionais especiais. Brasília: Corde, 1994.

FERNANDES, E. A função do intérprete na escolarização do surdo. In: Surdez e escolaridade, Desafios e Reflexões. Anais do II Congresso Internacional do INES, 17-19 de setembro de 2003.

QUADROS, Ronice Muller de. O tradutor e intérprete de Língua Brasileira de Sinais e Língua Portuguesa. Brasília: MEC/SEESP, 2004.

GODÓI, Patrícia. Atendimento Educacional Especializado para Alunos com Surdez https://patriciagodoi.blogspot.com/2012/05/atendimento-educacional-especializado.html

MOURA, M.C. O surdo: caminhos para uma nova identidade. Rio de Janeiro: Reiventer, 2000.

Como citar este artigo (Formato ABNT):

SILVA, Evilázia Matias de Sousa ; MENEZES, Aurelania Maria de Carvalho. A Inclusão do Surdo e seus Desafios na Educação Infantil. Id on Line Rev.Mult. Psic., Dezembro/2020, vol.14, n.53, p. 878889. ISSN: 1981-1179.

Recebido: 27/10/2020;

Aceito: 04/11/2020. 